\title{
La recepción de pedagogía del oprimido en Argentina: una hipótesis sobre la influencia freireana en la militancia juvenil de los años ' 70
}

\section{The reception of pedagogy of the oppressed in Argentina: a hypothesis on the freirean influence on youth militancy in the 1970s}

\section{A recepção da pedagogia do oprimido na Argentina: uma hipótese sobre a influência freireana na militância juvenil dos anos 1970}

\author{
Margarita R. Sgró* \\ A la memoria del Profesor Hugo A. Russo ${ }^{* *}$
}

\section{Resumen}

El 50 aniversario de la publicación de Pedagogía del Oprimido, inspira un sinfín de reflexiones pedagógicas, políticas, históricas. En Argentina, la presencia teórica de Paulo Freire fue decisiva para completar el terreno fértil de los movimientos emancipatorios de los años 70. Las juventudes politizadas, desarrollaban tareas que iban desde el "apoyo escolar y alimentario" en villas de emergencia (favelas en Brasil), hasta los movimientos de guerrilla urbana que habían decidido tomar el camino de la lucha armada. Eran y se percibían herederos de los Nacionalismos populares latinoamericanos, la Revolución cubana, la Teología de la liberación. En Argentina, esos movimientos tuvieran una expresión particular, su adscripción mayoritaria al Justicialismo. A comienzos de los años '70, Pedagogía del oprimido alentó una práctica concientizadora, preparatoria del terreno para la "liberación" de los pueblos. Pero esa práctica era única y original entre las pedagogías críticas. Su originalidad residía en dos cuestiones centrales, a) el oprimido era el protagonista de su propia educación por ser portador de una "cultura" silenciada, y b) el saber debía producirse mediante un "diálogo" entre sujetos iguales. En el marco político de la revolución posible, Pedagogía del Oprimido tuvo un protagonismo casi excluyente. El autor, lo sigue teniendo aun hoy.

Palabras clave: Pedagogía del oprimido. Movimientos juveniles. Liberación o dependencia. Argentina.

Recebido em 13/06/2020 - Aprovado em 28/09/2020

http://dx.doi.org/10.5335/rep.v27i3.12367

Es Doctora en Educación por la Universidad Estadual de Campinas, Profesora titular del Departamento de Educación de la Facultad de Ciencias Humanas de la Universidad Nacional del Centro de la Provincia de Buenos Aires. Área Filosófico-pedagógica. ORCID: https://orcid.org/0000-0002-6346-5572. E-mail: msgro@speedy.com.ar

* Vaya este texto como homenaje al Prof. Hugo Antonio Russo, recientemente fallecido. El Prof. Russo fue docente de la Facultad de Ciencias Humanas en la que me desempeño y orientador de mi tesis de Maestría, sobre Paulo Freire. 


\section{Abstract}

The 50th anniversary of the publication of "Pedagogy of the Oppressed" inspires endless pedagogical, political and historical reflections. In Argentina, Paulo Freire's theoretical presence was critical to complete the fertile ground for the liberation movement of the 1970's. The politicized youth performed various tasks that ranged from school and food support in shanty towns to urban guerrilla movements which had decided to take the path of armed struggle. They were and saw themselves as heirs of the popular Latin American Nationalisms, The Cuban Revolution, and Liberation Theology. In Argentina, these movements had a very specific expression: a predominant affiliation to "Justicialism". During the early 70's "Pedagogy of the Oppressed" fostered a conscientization approach, laying the ground for the "liberation" of the peoples. This approach was unique and original among critical pedagogies. Its originality lied in two core issues: a) the oppressed was the central figure of their own education as bearer of a "silenced culture" and b) new knowledge should be achieved through a dialogue between equal subjects. Within the political framework of the possible revolution, "Pedagogy of the Oppressed" had an almost exclusive role. The author still has it today.

Keywords: Pedagogy of the oppressed. Youth movements. Liberation or oppression. Argentina.

\section{Resumo}

O quinquagésimo aniversário da publicação da Pedagogia do oprimido inspira infindas reflexões pedagógicas, políticas e históricas. Na Argentina, a presença teórica de Paulo Freire foi decisiva para completar o terreno fértil dos movimentos emancipatórios dos anos 1970. As juventudes politizadas desenvolviam tarefas que iam desde o "apoio escolar e alimentício" em villas de emergencia (favelas no Brasil) até os movimentos de guerrilha urbana que haviam decidido tomar o caminho da luta armada. Eram e se percebiam herdeiros dos Nacionalismos populares latino-americanos, a Revolução Cubana e a Teologia da libertação. Na Argentina, esses diferentes movimentos tiveram uma característica particular, seus membros aderiram majoritariamente ao Justicialismo. No começo dos anos 1970, a pedagogia do oprimido impulsionou uma prática conscientizadora, preparatória do terreno para a "libertação" dos povos. Porém, essa prática era única e original entre as pedagogias críticas. Sua originalidade estava em duas questões centrais: a) o oprimido era o protagonista de sua própria educação, por ser portador de uma "cultura" silenciada; e b) o saber deveria produzir-se mediante um "diálogo entre sujeitos iguais". No marco político da revolução possível, Pedagogia do oprimido teve um protagonismo quase excludente. Seu autor continua sendo protagonista ainda hoje.

Palavras-chave: Pedagogia do oprimido. Movimentos juvenis. Liberação ou dependência. Argentina.

\section{Introducción}

La obra Pedagogía del Oprimido, publicada en el año 1970, fue y es interpretada de muchas maneras, Paulo Freire es frecuentemente víctima de esas interpretaciones de las que, en general, la más extendida expresa que su libro, publicado en el exilio y con un primer capítulo dedicado a hablar de la opresión de los pobres, es solo un método de enseñanza, que como tantos otros se esfuerza en optimizar el aprendizaje de la lecto-escritura, a analfabetos adultos que precisan "aprender" de un modo diferente a como lo hace un niño. Es una extraña manera de extirpar la criticidad del proceso de lectura y la politicidad de cualquier práctica pedagógica. Es también una manera de debilitar la crítica social y política para tornar 
instrumental lo que no lo es. Ese conjunto de incomprensiones traspasa a la consideración pedagógica para constituirse en una interpretación política de la que, frecuentemente, las derechas reniegan.

En la actualidad, podemos encontrar reacciones mucho más violentas y menos pretendidamente academicistas de rechazo, no solo a la obra del autor, sino a su enorme influencia transformadora.

Si en general, las derechas optan por este reduccionismo metodológico, las izquierdas tradicionales no le perdonan la concepción sobre cultura popular y religiosidad que impregna su trayectoria, como tampoco le perdonan su latinoamericanismo, ampliado luego, a todos los pueblos del Tercer Mundo. En Argentina, las izquierdas tradicionales han sido fuertemente antipopulares.

El análisis que haremos en este artículo remite, directa y específicamente a lo que creemos, es la lectura más aproximada a la obra y a la vida del autor. No solo la que precedió a Pedagogía del Oprimido, sino también los textos posteriores que destacan una trayectoria político-pedagógica riquísima, documentada históricamente. Porque Pedagogía del oprimido es el producto de una época en la que el horizonte revolucionario cooptó a la acción política y, en la que el modelo de revolución podía ser más o menos el de la Revolución Cubana contra el imperialismo norteamericano, pero también podía provenir de otras perspectivas de transformación social, antiimperialistas que levantaran la bandera de la igualdad y la justicia social. En este sentido, los Nacionalismos populares de las décadas de los años ' 40 y '50 fueron también representativos de una praxis emancipadora de características singulares, en las que la educación del "pueblo" se vio como una necesidad impostergable.

Un nuevo sujeto nacía a la vida política, las democracias, aunque formales, se afianzaban a partir de la incorporación masiva de la población a un conjunto de derechos, entre los principales se contaba a la educación y la salud públicas, pero también todos los derechos sociales a una vivienda y a un salario dignos, aguinaldo, vacaciones pagas. Derechos que hasta el momento de la irrupción del peronismo en Argentina, eran privilegios de los que disfrutaban unos pocos.

En una sociedad muy desigual esos derechos costaron muchas batallas que debían dar los trabajadores, para conseguirlos primero y luego defenderlos, por eso la formación política, el valor de la organización y de la sindicalización fueron ejes que sustentaron el proyecto político del Movimiento Nacional Justicialista.

La consideración de la educación que debía recibir ese nuevo sujeto dividió las aguas del debate político-pedagógico. ¿Qué es la educación popular? ¿Cómo debe 
ser? ¿Ese nuevo sujeto de derechos, debe ser elevado a la cultura oficial? ¿O debemos reconocer en él una cultura silenciada?

En Argentina, los trabajadores venían de una historia de luchas en las que no se ahorró sangre, torturas, asesinatos masivos. Pero esas batallas, casi siempre perdidas por los trabajadores, cristalizaron en un hecho histórico, el 17 de octubre de 1945, fecha en la que, la mayoría de los historiadores, coinciden en señalar como la fundación del Peronismo. Desde ese momento y hasta la actualidad, este Movimiento ha tenido una influencia decisiva en la política y en la cultura de nuestro país. El Peronismo fue, en el gobierno o fuera de él, determinante para la historia contemporánea de Argentina. Perón gobernó desde 1946 hasta 1955 en que fue derrocado por un golpe de Estado, se exilia en España y después de dieciocho años retorna en 1973. En el transcurso de esos años las organizaciones de la sociedad civil, primordialmente los sindicatos en su mayoría peronistas, los pequeños grupos de militantes que actuaban en la clandestinidad, mantuvieron viva la defensa de los derechos, se afianzó la lucha de los trabajadores combativos, preparando al mismo tiempo el Retorno de Perón. A ese período se lo conoce como el de la "Resistencia Peronista", fueron esos militantes los gestores del retorno que finalmente se concretaría en 1973, en ese año Perón vuelve a ser Presidente y muere el 1 de julio de 1974. Fueron tiempos de una historia trágica a los que en 1976, sobrevino una feroz Dictadura.

La hipótesis de este trabajo es que la enorme influencia del pensamiento freireano, en los años 70, se debió en parte, a la coincidencia con el ideario del Peronismo, especialmente encarnado en una militancia juvenil, que leyó su tiempo como el de la realización de la utopía revolucionaria. Los actores de ese compromiso fueron los jóvenes universitarios, los trabajadores sindicalizados, muchos de ellos pertenecientes a grupos de la Iglesia Católica, sobre todo al Movimiento de Sacerdotes para el Tercer mundo, fundado en la provincia de Córdoba en el mes de mayo de 1968, que compartía fervientemente los principios del Episcopado Latinoamericano, expresados en el Documento de Medellín en el mes de septiembre del mismo año. Ambos movimientos de Iglesia se referenciaban en la enorme transformación que significó el Concilio Vaticano II.

Pedagogía del Oprimido, llega en el momento en que la tarea de formación pedagógica en las "villas de emergencia", en los barrios obreros, en las organizaciones de base de la Iglesia católica, se tornaba preeminente, "no habrá liberación que no provenga de los oprimidos", decía el Padre Carlos Mugica ${ }^{1}$, de los postergados, de los villeros ${ }^{2} \mathrm{y}$ de los trabajadores, que aún considerados como un sector 
heterogéneo, serán los estandartes de la liberación. Encuadrados en el Peronismo, buscaban forzar su radicalización hacia un socialismo nacional.

También en el año 1968, en el mes de marzo se funda la Confederación General del Trabajo de los Argentinos, la CGT de los argentinos, liderada por Raimundo Ongaro, que organizó al sindicalismo combativo de diferentes sectores de izquierda con mayoría de la izquierda peronista. Las relaciones entre esa confederación sindical y el Movimiento de Sacerdotes para el Tercer mundo, fue muy fluida. En ese contexto, "La pedagogía del oprimido resulta ser tanto un análisis pormenorizado de la reproducción de las interrelaciones entre los hombres de una misma sociedad inmersas en relaciones estructurales de dependencia, cuanto una 'estrategia comunicativa' de superación." (RUSSO; SGRÓ, 2001, p. 70).

\section{El contexto histórico de recepción}

Es temprana, en el pensamiento crítico latinoamericano la voluntad de liberación enraizada en los movimientos independentistas de comienzos del siglo XIX. A ellos estuvo asociada una pedagogía crítica que entendió con claridad la necesidad de formar a los pueblos originarios, a las mujeres, y a los negros o sus descedientes, porque ellos serían los actores de la verdadera emancipación. Ejemplo de estas ideas tempranas fueron Simón Rodriguez, maestro de Simón Bolívar, o José Martí, el gran poeta y educador cubano, entre otros. Su prédica, a favor de la cual fueron capaces de tomar las armas, conspirar y hasta morir, se asentaba sobre el derecho a la autodeterminación de los pueblos, al desenvolvimiento de sus culturas nativas y la lucha contra la desigualdad. Por ello, fueron lectores de Juan Jacobo Rousseau y practicaron un liberalismo, cuyo anhelo era poner fin a la esclavitud. Es así que en esos primeros tiempos, la inclusión de todos, hombres y mujeres, negros y mulatos en la vida social, era una preocupación de los próceres de la independencia. Planteo este tema porque en la historiografía revisada del Peronismo se coloca como una línea histórica, la que va de aquellos próceres de la Primera independencia hasta los que a principios del siglo XXI se denominaron como corrientes posneoliberales, o socialismos del siglo XXI, y en Argentina "nacionalismos populares" cuya raíz primera está en el Peronismo.

La línea que une esas sucesivas batallas puede resumirse en la oposición: Derechos contra privilegios, esa parece ser una constante en la lucha de los pueblos contra diversas formas de dominación. Éstas, pueden presentarse en forma de Dictaduras sangrientas como las que dominaban el panorama político en 1970, o 
pueden, como ha ocurrido más recientemente, llegar de la mano del voto popular. Lo que reactualiza dramáticamente la cuestión de la "formación" o de la "educación del pueblo". Pero esa es una historia reciente. "Freire es un intelectual representativo de su época, se nutre y a su vez nutre el pensamiento que se va generando en las décadas de los '60 y de los '70 a partir de un nuevo diagnóstico político, sociológico, antropológico y filosófico." (RUSSO; SGRÓ, 2001, p. 53).

La Argentina de los años '70 era, como otros países latinoamericanos, un escenario propicio para pensar en términos dicotómicos la política. La lectura de que el conflicto central no era un conflicto Este-Oeste, sino un conflicto entre el Norte y el Sur, estaba muy bien analizada en una corriente de pensamiento que tuvo también mucha influencia en Freire y que se denominó Teoría de la Dependencia ${ }^{3}$, cuyo eje central era que los pueblos pobres debían su pobreza a la lógica de explotación que aplicaba el imperialismo norteamericano.

Esa percepción también estuvo tempranamente en el Peronismo, el tinte nacionalista de sus políticas, la construcción de un Estado fuerte y presente, se conjugaron con la oportunidad que brindó el fin de la Segunda Guerra Mundial para sustituir importaciones. La nueva nación habría de construirse sobre tres principios que están, aun a pesar de la globalización, muy presentes en el debate político de nuestro país, ellas son: Soberanía política, Independencia económica y Justicia social. Mientras en otros países esos principios fueron estandartes de las izquierdas no tradicionales, en Argentina quedan en manos del Peronismo, que se torna el representante de los intereses populares, de los trabajadores, de los pobres, de los excluidos.

El Partido Socialista, en cambio, adhería a una vieja dicotomía de Civilización o Barbarie que había expresado la llamada Generación del '80. Una generación que dirigió la política y la cultura Argentina en la segunda mitad del siglo XIX hasta aproximadamente 1930. Una élite modernizadora y europeizante que, aunque contó entre sus representantes, algunos matices críticos, acaba constituyendo una oligarquía terrateniente y parasitaria, que se benefició del reparto de tierras entre pocas familias. Éstas tierras habían sido quitadas a los indios y los gauchos, mediante un proyecto de exterminio feroz al que se llamó "Campaña del desierto", un "desierto" que estaba habitado, por el que tuvieron que guerrear durante años con sus primeros ocupantes o sea, con los dueños reales de la tierra.

Civilización o Barbarie, marcó la historia Argentina desde el siglo XIX ${ }^{4}$ y se reavivó cuando irrumpe el Peronismo en 1945. A partir de allí la escisión fue Peronismo-Antiperonismo, en un juego de opuestos en el que cada uno va asumiendo su 
identidad de manera relacional, así lo expresa Alejandro Grimson, en su reciente libro ${ }^{5}$.

"Peronistas" fue la categoría de identificación que más vertiginosamente crecería a partir de julio de 1945, asociada de distintos modos a la nacionalidad, lo criollo, los descamisados, los cabecitas negras, los obreros, los trabajadores, el pueblo. Setenta años después, con drásticos cambios de significado a lo largo de su historia, el término tiene plena vigencia. (2019, p. 104).

El antiperonismo, que nació al mismo tiempo que el peronismo, fue y es de derecha y de izquierda, la derecha le endilgaba el mote de dictadura yproyecto demagógico por la adhesión masiva que conseguía de parte de los trabajadores, de las organizaciones sindicales y por una fenomenal distribución de la renta que llegó a cada rincón de la nación bajo la consigna ordenadora de generar empleo y devolver la dignidad al "pueblo". La izquierda rápidamente lo identificó como fascista, e inmediatamente comenzaron a hablar de la Dictadura peronista y de la capacidad de manipulación, que el liderazgo de Perón tenía sobre las masas populares, a quienes no se le reconocía ninguna autonomía. La idea repetida hasta el presente es la de un manso rebaño sin voluntad propia.

Con respecto al peronismo, izquierda y derecha hacen un coro de reclamos republicanistas. Aunque ambas fuerzas, estuvieron comprometidas en el Golpe de Estado de 1955, participaron de ese gobierno de facto y de todos los posteriores y algunos de sus miembros más encumbrados, frecuentemente recurrieron a los militares como salida "democrática".

Mientras las élites quedaron representadas por los partidos tradicionales incluido el Radicalismo, los nuevos sectores que demandaban derechos e inclusión social se identificaban mayoritariamente con el Peronismo. No es este el lugar para explicar con más detalle la obra que el primer gobierno peronista realizó desde 1945 hasta 1955, tampoco es el lugar para narrar la destrucción a la que fue sometida una vez que cae el gobierno.

Sin embargo, la herencia cultural que dejó aquel período explica mucho de la pregnancia del peronismo hasta nuestros días. "Existieron 'populismos' en diversos países latinoamericanos, pero aunque ha habido movimientos que perduraron varios años ninguno tuvo la persistencia del peronismo. El gobierno de Vargas en Brasil no generó ‘varguismo' y algo similar podría decirse de otros países.” (GRIMSON, 2019, p. 51). A la distancia, su singularidad resiste las clasificaciones más o menos tradicionales y por ello hay autores que hablan de cuatro peronismos y otros de cinco al incluir los gobiernos de Néstor y Cristina Kirchner (HOROWICZ, 2015). 
Habría ahora un sexto, representado en el gobierno actual de Alberto Fernandez, en esa heterogeneidad signada también por la marca particular de cada tiempo, las tres ideas centrales, nunca dejan de ser mencionadas, aun cuando en algunos momentos haya asumido una cara neoliberal, fue en los años '90 cuando gobernaba Carlos Menem.

Por lo tanto, la escisión entre peronismo y antiperonismo, presente en la cultura política de Argentina, el fuerte rechazo de sectores de derecha y de izquierda tradicional, las variadas formas de desvalorizarlo y desvalorizar a sus adherentes como incultos, bárbaros, malvivientes, marginales se debe, sin dudas, al odio que generó el enorme proceso de igualación social, intolerable para los dueños de la argentina. Por eso, el antiperonismo es paralelo al peronismo y esa "grieta" puede perfectamente plantearse en tiempo presente. La virulenta reacción del antiperonismo muestra también el carácter profundamente racista de la cultura política argentina (GRIMSON, 2019, p. 104 y ss).

Es interesante destacar que la categoría identificatoria de peronista se generó por los insultos de las clases dominantes, blancas y porteñas que vivían en Buenos Aires, no en la provincia, sino en la Capital. Ellos creían que los trabajadores no debían ocupar ni el centro de la ciudad europeizada ni el centro de la vida pública. Así, el concepto de "descamisados" se usaba para referirse despectivamente a los trabajadores de fábricas, trabajadores de la construcción, llegados del interior o los trabajadores de los frigoríficos; "cabecitas negras" para referirse a los argentinos del interior profundo, "negros", "grasas", "aluvión zoológico", fueron insultos que el peronismo asumió como propios, para afirmar una nueva identidad, del demérito al mérito de pertenecer a una clase que en el ideario peronista sería la responsable de cambiar la historia de Argentina. Pues, si finalmente un mundo más justo era posible, vendría del "subsuelo de la patria sublevado", dice un intelectual del peronismo que se llamó Raúl Scalabrini Ortíz $z^{6}$, que describe con esas bellas palabras el 17 de octubre de 1945, cuando las masas de trabajadores llegan a Plaza de Mayo para pedir la liberación del entonces Coronel Perón que estaba preso. Perón fue liberado y se convierte en Presidente en 1946. A partir de ahí se escribe la historia contemporánea de nuestro país.

Este breve desarrollo explica por qué en Argentina a diferencia de otros países latinoamericanos, los "oprimidos" se identificaron con este movimiento complejo y vital que cada tanto renace con su mejor tradición.

La perspectiva emancipadora, el convencimiento de que los derechos se ganan y se defienden a veces violentamente, como ha sido frecuente en Argentina, llevó a 
tener una genuina preocupación por la formación del pueblo y de los trabajadores. Su incorporación y la de los sectores populares a la vida pública, requirió de un proceso de formación política que emprendieron los sindicatos y grupos politizados que pretendían, en primer término, la creación de una conciencia social, que no era estrictamente conciencia de clase, porque el propio Perón decía que este antagonismo debía ser superado por el de una "comunidad organizada" . Es posible pensar que Freire no estaría muy de acuerdo con Perón habida cuenta de su crítica a los líderes personalistas, y a la idea desarrollada en la última parte de su texto, en que una verdadera revolución resultará del diálogo entre el líder y su pueblo, lo dice refiriéndose a la Revolución cubana. Sin embargo, esa es una historia contrafáctica que no podemos comprobar. ${ }^{8}$

La idea de "Comunidad organizada" es todavía hoy discutida como una de las nociones fundamentales, constituida por un modo de asociación de la comunidad que Perón llamó Organizaciones Libres del Pueblo" (OLP) como por ejemplo, clubes de barrio, asociaciones de profesionales, de trabajadores, fundaciones, cooperativas, organizaciones de productores, mutuales, etc. Este modelo de organización no dependía del Estado, debía interactuar con el Estado y multiplicarse hacia la sociedad civil. Aúnada a la idea de que el individuo no puede realizarse y ser feliz en una comunidad que no se realiza, dice Perón en un extenso discurso histórico, proferido en 1949, con el que cierra el Primer congreso nacional de Filosofía realizado en la Provincia de Mendoza9 .

Esa doctrina fue articulándose dificultosamente después de 1955. Durante el exilio y proscripción de Perón era él mismo el que se encargaba de mandar, a través emisarios, sobre todo sindicalistas, "cintas" grabadas con su voz, explicando diversos temas que eran luego discutidos por los trabajadores en los sindicatos o en la clandestinidad durante la Dictadura que sucedió a su primer gobierno.

Lo que despectivamente la derecha y la izquierda llamaba adoctrinamiento, era el trabajo de formación política que incluía el debate sobre los planes de gobierno que se repartían impresos en las fábricas, en los frigoríficos para que los propios trabajadores se conviertan en difusores y responsables de su explicación y sobre todo, protagonizaran la defensa de sus derechos. Esa organización, en que confiaba ciegamente el Peronismo fue lo que permitió su supervivencia a través de 75 años.

Una pedagogía que se propone como un camino hacia la liberación, que critica a los opresores como responsables de generar una situación estructural de injusticia, coloca en el centro de la escena a los pobres y los alienta a luchar por sí mismos, reforzando el ideario de que la justicia solo pueden buscarla los que sufren desi- 
gualdad y desprecio. “¿Quién mejor que los oprimidos se encontrará preparado para entender el significado terrible de una sociedad opresora?” (FREIRE, 1973, p. 40).

El comienzo de los años 70 fue una época de política de masas, de organización popular y debates sobre la necesaria transformación social que convocó a la militancia política a miles de jóvenes provenientes de las clases bajas y medias que ya no entendían la participación social solo como resistencia a los poderes establecidos, sino como una forma de luchar, de muy diversas maneras, por la emancipación, una de ellas, fundamental, era aportar a un proceso de formación del pueblo, víctima de las más diversas injusticias. El pueblo pobre pasaba a ser el protagonista de los desvelos teóricos, ideológicos y políticos de un nuevo tiempo de liberación. No se podía esperar que los poderosos instalaran la justicia distributiva, había que sacarles la riqueza de la que se habían apropiado. Esto requería un proceso de enseñanza y aprendizaje que tenía que partir de los "condenados de la tierra', de los oprimidos, de los desarrapados del mundo y de los que con ellos realmente solidaricen." (FREIRE, 1973, p. 40).

Paralelamente en los '70, la lucha entre la derecha y la izquierda peronista se profundiza, la ruptura del movimiento obrero ocurrida en 1968, por la fundación de la CGT de los Argentinos, la creación del Movimiento de Sacerdotes para el Tercer Mundo, su compromiso político partidario, llevan la pelea entre izquierda y derecha al interior del peronismo, ese conflicto terminó en una violencia interna en la que el diálogo fue reemplazado por miles de muertos, algunos notables, que un bando le "tiraba" al otro como símbolo de su fuerza política. Perón, ya anciano y con condiciones políticas muy diferentes a aquellas de 1945 cuando tomó el poder por primera vez, no pudo resolver esa lucha interna y podríamos decir que aun hoy, cuando el peronismo es el principal partido de la coalición gobernante, pervive sin la estridencia y sin violencia explícita, pero como una rémora que no se ha discutido profundamente, tal vez, porque como dice Grimson, en el texto citado, ya no es un problema del peronismo solamente, sino de una ruptura que existe entre peronismo y antiperonismo en la cultura política argentina y podríamos agregar también, de los bordes difusos de las ideologías, en una época de retroceso político.

Los 70 pusieron todo en debate, la colonización cultural y la explotación económica que se asienta sobre la colonización cultural, mientras Freire escribía Pedagogía del Oprimido, el chileno Ariel Dorfman escribía, junto a Armand Mattelart, un precioso texto denominado "Para leer al pato Donald", en el que analizaban la ideología oculta tras las difundidas historietas de Disney y develaban la máquina de dominio cultural, escondida en esa fabulosa industria, llamada Disneylandia. 
No fueron los únicos, en toda América Latina se desarrolló un movimiento denominado "comunicación popular", dedicado a develar los mecanismos por los cuales el Imperio distribuía cultura "enlatada", prefabricada en serie, con el fin de colonizar las culturas de los países periféricos o del Tercer mundo.

A esa generación de los años ‘70, dice Grimson (2019, p. 145):

Les tocó en suerte vivir una época extraña. El mundo de la Guerra Fría, escindido entre el occidente capitalista y el comunismo soviético. El mundo de la Revolución China, de la liberación de Argelia y de la Revolución Cubana. El mundo de Mayo del 68 y del Cordobazo. El mundo de Allende y el Che Guevara. Un mundo en el que los militantes creían que su acción podía cambiarlo todo, que lo que ellos hicieran podía incidir de manera decisiva en los acontecimientos.

Este pequeño raconto de textos que constituyeron la pedagogía emancipadora de un tiempo, estaría incompleto si no mencionara que en el año 1971, el escritor uruguayo Eduardo Galeano publica "Las venas abiertas de América Latina", en Argelia, unos años antes, Franz Fanon publica "Los condenados de la Tierra" referido a las luchas por la liberación de Argelia, con prólogo de Jean Paul Sartre. El teólogo peruano Gustavo Gutierrez, publica el libro fundante de la "teología de la liberación”, también en 1971. Y así podríamos seguir con otros textos que se convirtieron en emblemas de un tiempo singular.

En ese contexto político radicalizado con miles de jóvenes volcados a la militancia social y política se preparaba el fin de la Dictadura del General Lanusse, el retorno del General Perón y por fin la autorización a elecciones libres, en las que pudiera presentarse el propio Perón, que además de exiliado estaba proscripto.

En ese proceso, un sector muy importante de la Iglesia católica, la más comprometida con la "opción preferencial por los pobres" que predicaba el Documento de Medellín, había entendido que estar con los pobres y luchar por su liberación estaba muy lejos de la lógica caritativa o asistencialista que tradicionalmente se pregonaba, esa perspectiva significó una escisión importante también en la Iglesia argentina. "Dicen los obispos: 'Cuando Dios revela su designio divino (...) la justicia no aparece solo como un don personal (...) sino como un estado del pueblo'.” (P. Mugica) (VERNAZZA, 1984, p. 77).

El Movimiento de Sacerdotes para el Tercer Mundo, MSTM tuvo un papel preponderante en la Iglesia argentina y latinoamericana. Cuando en el año 2018 se cumplieron los cincuenta años de su fundación, uno de sus principales mentores publicó un libro que reúne los debates de la época y todos los documentos que emitieron en su corta vida como Movimiento, el Padre Domingo Bresci dice: “(...) 
los integrantes de este Movimiento -hombres de fe- compartían la 'indignación evangélica' ante la injusticia y se propusieron seguir a Cristo Liberador y Servidor, desde una Iglesia Encarnada, Pobre, Samaritana y Profética." (2018, p. 10).

Como ya lo hemos expresado en el texto dedicado al pensamiento freireano (RUSSO; SGRÓ, 2001, p. 34 y ss), esa percepción sobre el oprimido, sobre la liberación y la humanización, conjuga la raíz crítico-marxista, con la mirada de la Teología de la liberación.

Para finalizar, si hay un poco de verdad en la hipótesis que intenté defender, voy a plantear ahora las cuestiones propiamente pedagógicas que anuncié en la introducción a este texto.

¿Qué aportó específicamente Pedagogía del Oprimido al debate político pedagógico? ¿Porqué caló tan hondo en la militancia de la época? Dijimos en la introducción de este trabajo que la originalidad de Pedagogía del oprimido, está, por un lado, en la consideración de la cultura popular como punto de partida de una educación problematizadora cuyo norte es la liberación, por otro lado, el diálogo como método, que reconoce al "otro" como un igual.

Freire, como los autores antes mencionados, por participar del debate de su tiempo decidido a comprometerse con los oprimidos, entendió el peso de la cultura en la dominación y explotación de los pueblos. Consecuentemente, pensó en el sustrato que permitiría enfrentar semejante poder, ese sustrato era el de la cultura popular, se movió en la delgada línea que entiende que la educación es invariablemente una acción con otros, en la que influimos sobre otros, pero esa influencia estaba destinada a develar la cultura silenciada por siglos de opresión.

(...) el que el acercamiento a las masas populares se haga, no para llevar un mensaje 'salvador' en forma de contenido que ha de ser depositado, sino para, dialogando con ellas, conocer, no solo la objetividad en que se encuentran, sino la conciencia que de esta objetividad estén teniendo, (...) En verdad lo que debemos hacer es plantear al pueblo, a través de ciertas contradicciones básicas, su situación existencial, concreta, presente, como problema que a su vez, lo desafía y haciéndolo le exige una respuesta, no a un nivel intelectual, sino al nivel de la acción. (FREIRE, 1973, p. 114-115).

Esa acción pedagógica implica por parte del educador estar abierto a la transformación que surja de una nueva interpretación del mundo, de una creación que solo el "diálogo" entre dos sujetos iguales, puede producir. En este sentido, el debate político es un ámbito propicio para poner en juego saberes surgidos de la experiencia propia, la experiencia de la opresión, del desprecio, del hambre. La "formación política" asumida con mucha seriedad, por las organizaciones sindicales y los militantes de base, se ajustaba perfectamente a la noción tan controversial de que 
"nadie educa a nadie, todos nos educamos entre todos". Porque la cultura popular es un campo de saberes desvalorizados por la cultura erudita u oficial, sin embargo contiene saberes extremadamente valiosos, que funcionan además como un tamiz capaz de filtrar nuevos saberes, nadie, ni el trabajador más rústico es una tabla rasa, todos poseemos una historia y una cultura vivencial que nos constituye.

La herencia de la pedagogía freireana setentista, permitió en los años ' 80 y hasta nuestros días, reelaborar una mirada sobre la educación del pueblo, que ya no aspiraba a la revolución pero que aun así, tenía la potencia de colocar a todos los hombres como creadores de cultura y no solo destinatarios de la cultura que otros crean.

En los años 70 al calor de la revolución posible, esa discusión pedagógica se actualizó y como sucede con frecuencia, se radicalizó. Si de universalizar derechos se trata, si de generar una sociedad más justa se trata, el nuevo sujeto no puede simplemente recibir la cultura hegemónica y aceptarla, hay que partir de su propia palabra, porque lo que está en juego es el fin de la opresión y ella es, en primer término, la que deviene de la cultura del silencio producida por tantos siglos de explotación.

Ese debate pedagógico está vigente, por la fortaleza que en Argentina tiene la escuela pública estatal. Dos modelos, que cada vez son menos opuestos, se disputan el nombre de Educación popular, el modelo sarmientino hegemónico y un cada vez más presente modelo freireano en la escuela pública estatal. Pero esa es otra discusión.

\section{Conclusiones}

Pedagogía del Oprimido, llega en medio de ese escenario político convulsionado en el que intelectuales, artistas, cineastas, periodistas también estaban comprometidos. Freire completa desde un punto de vista latinoamericano, la crítica que hacía falta a una educación incapaz de reconocer los saberes populares, la potencia liberadora de la cultura del pueblo. El texto radicalizaba una crítica que develaba hasta qué punto la educación podía ser un vehículo de dominación.

Aun cuando a la distancia podemos y debemos criticar algunas ideas de Pedagogía del Oprimido, Freire fue en el sentido amplio del término el último pedagogo latinoamericano, aquel que colocó el carácter político de la educación como eje del debate y lo hizo a lo largo de toda su vida, ignorarlo, ingenua o deliberadamente, restringe y debilita la energía de la crítica.

Hace un tiempo, participé como invitada de la sección "Conversando con educadores” de esta misma Revista. Allí conté como llegó a mí, en 1977, plena 
Dictadura, la noticia de que había un pedagogo, un educador que hablaba de los Oprimidos, de los pobres, y sobre todo se preocupaba en educar para la Liberación. Eran tiempos de una masacre planificada, de tortura y desaparición forzada de personas, sean estudiantes, obreros que reclamaban derechos o simplemente otras personas que enseñaban en una Villa de emergencia, o que tenían un comedor popular u otras, al azar, porque el objetivo era hacer sentir que todos estábamos en riesgo. Fue en esos años terribles, que en una librería que vendía libros y revistas usadas conseguí un ejemplar de Pedagogía del Oprimido, editado por la editorial Siglo XXI en el año 1973, para ese año el libro llevaba ocho ediciones.

Yo saludo la iniciativa de esta Revista y de todos los homenajes, muchos en Argentina, que se hagan por los 50 años de publicación de este libro, es el deber de sostener, en un tiempo radicalmente opuesto, el espíritu de la crítica política, porque renunciar al horizonte revolucionario no es lo mismo que renunciar a formas de vida más igualitarias y justas. Y creo, que en este punto se encuentra otra de las grandes virtudes de un pensador como Freire, que aun cuando ya lleva más de veinte años fallecido nos permite enfrentar el empobrecimiento cultural y la docilidad intelectual con la que aceptamos que la realidad no puede cambiarse. Freire es un espejo en el que es posible leer nuestro tiempo como un retroceso a la barbarie, como un retorno histórico a la minoría de edad. Pero también su pedagogía interpela nuestra criticidad y nos ayuda a no ceder a tantas tentaciones de frivolidad intelectual y mercantilización, estímulos que el neoliberalismo nos pone por delante. Mantener viva la memoria de un autor, de un texto, como en este caso, es parte de un acto de Resistencia imprescindible contra la barbarie y la violencia. Pues, aun para quienes no piensan ganar la batalla, las ideas de igualdad, libertad y justicia social, siguen siendo el piso de la crítica política y pedagógica en América Latina.

\section{Notas}

1 El Padre Carlos Mugica, fue uno de los representantes más importantes del Movimiento de Sacerdotes para el Tercer Mundo, en un momento en que muchos de ellos, adhieren explícitamente al Peronismo, trabajando en las "villas de emergencia". Hoy, la "villa de Retiro", $\mathrm{n}^{\circ} 31$, lleva su nombre porque fue uno de los asentamientos donde más trabajó, era el Párroco de la capilla Cristo obrero. Esta historia está contada por el Padre Jorge Vernazza, amigo personal del sacerdote, en un libro del año 1984, que ese llama, Padre Mugica, una vida para el pueblo. Mugica fue asesinado, el 11 de mayo de 1974, después de una misa, por una organización armada llamada Triple A (Alianza Anticomunista Argentina), uno de los grupos de la Derecha Peronista que comenzaría un baño de sangre indetenible, profundizado luego por el "Terrorismo de Estado" que implantó la Dictadura de 1976.

2 Se denomina "Villero" al habitante de una Villa de emergencia, también llamada Villa miseria, la palabra villero tiene un tono despectivo en la cultura argentina, "negro villero" es un calificativo proferido como ofensa. 
3 Cf. Russo y Sgró (2001, p. 64-72).

4 Cf. Sgró (2017).

5 Grimson (2019).

6 Raúl Scalabrini Ortiz. Tierra sin nada, tierra de profetas, Buenos Aires, Plus Ultra, 1973, p. 55. Citado por Felipe Pigna e disponible en: https://www.elhistoriador.com.ar/.

7 Sería interesante indagar también las coincidencias entre el pensamiento freireano y el peronismo, por haber encarado un camino estrecho que los separa del Marxismo, sin renunciar a la transformación social.

8 Cf. Freire (1973).

9 Cf. Primer Congreso Nacional de Filosofía, Mendoza, 1949. Disponible en: http://www.filosofia.org/ mfb/1949a128.htm\#00 ó Perón, J. Una comunidad organizada y otros discursos académicos. Buenos Aires: MacachaGuemes, 1973. Compilado por Enrique Pavón Pereyra.

\section{Referencias}

BRESCI, D. Historia de un compromiso. MSTM A cincuentaañosdelMovimiento de Sacerdotes para el Tercer Mundo. Buenos Aires: GES-Comunicación, 2018.

DOCUMENTOS Finales de Medellín. II Conferencia General del Episcopado Latinoamericano. Buenos Aires: Ediciones Paulinas, 1981.

DORFMAN, A.; MATTELART, A. Para leer al Pato Donald. Comunicación de masas y colonialismo. Buenos Aires: Siglo XXI, 1972.

FANON, F. Los condenados de latierra. Montevideo: Aquí y Ahora, 1972.

FREIRE, P. Pedagogía del oprimido. 8. ed. Argentina: Siglo XXI, 1973.

GALEANO, E. Las venasabiertas de América Latina. 35. ed. Buenos Aires: Siglo XXI, 1983.

GRIMSON, A. ¿Qué es el Peronismo? De Perón a los Kirchner, el movimiento que no deja de conmover a la política argentina. Buenos Aires: Siglo XXI, 2019.

GUTIERREZ, G. Teología de la liberación, perspectivas. Salamanca : Ediciones Sígueme, 1972.

HOROWICZ, A. Los cuatroperonismos. Buenos Aires: Edhasa, 2015.

RUSSO, A.; SGRÓ, M. Paulo Freire, el pensamiento latinoamericano y la recuperación de la racionalidad dialógica. Tandil, Argentina: Universidad Nacional del Centro de la Provincia de Buenos Aires, 2001.

SGRÓ, M. Educación, civilización y barbarie. In: TREVISAN, A.; TOMAZETTI, E.; ROSSATTO, N. (org.). Filosofia e educação. Ética, Biopolítica e Barbárie. Curitiba, PR: Appris Editora, 2017. p. 185-198.

SGRÓ, M. La Pedagogía dialógicacomo condición de la Teoría crítica de la educación. Revista Contextos de Educación, Facultad de Ciencias Humanas, Universidad Nacional de Río Cuarto, Córdoba, Argentina, 2005.

VERNAZZA, J. (comp.). Padre Mugica, una vida para el pueblo. Edit Pequén, 1984. 